\title{
Managing the Quality of Cross-Border Higher Education in Zimbabwe
}

\author{
Evelyn Chiyevo Garwe
}

\author{
Correspondence: Evelyn Chiyevo Garwe, Deputy Chief Executive Officer for the Zimbabwe Council for Higher \\ Education, Zimbabwe
}

Received: January 9, 2015

Accepted: January 23, 2015 Online Published: February 10, 2015

doi:10.11114/jets.v3i2.634

URL: http://dx.doi.org/10.11114/jets.v3i2.634

\begin{abstract}
A study on investigating the issues of quality associated with cross-border higher education was carried out using the case study approach focusing on Zimbabwe. The methodology involved document analysis of the cases of regulation and accreditation of cross-border higher education providers and assessment of qualifications acquired from foreign higher education providers as well as interviews with staff from the national quality assurance body. The findings revealed that internationalisation of higher education, does offer several prospects and advantages but it can also negatively impact on the quality of higher education provision if certain activities are left unchecked. These include sub-standard and dubious foreign higher education providers who often enrol students who do not meet the minimum entry requirements as well as degree mills who sell qualifications to clients who do not merit obtaining them. Out of all the qualifications assessed from 2009-2013, 28 percent where found not comparable with similar local qualifications in terms of curriculum content, rigor, duration of study and entry requirements. The lessons from the study include the need for higher education institutions to enrol students who meet nationally agreed entry requirements as well as introducing qualifying courses before admission of those who do not initially meet the required standards for entry. Quality assurance bodies and institutions of higher learning should continue to collaborate with similar bodies globally in order to share best practices on quality assurance issues and setting of minimum standards.
\end{abstract}

Keywords: cross-border higher education, registration, accreditation, quality, comparability

\section{Introduction}

Cross boarder higher education has been acknowledged for greatly enhancing the availability of human resources and the concomitant socio-economic development of countries (Knight 1999, Ninnes \& Hellstén 2005). Bashir (2007) reported that most developing countries are unable to match the continuous rise in demand for higher education locally and hence they resort to foreign higher education providers to narrow the gap. These foreign providers can either be based abroad or they have branch campuses in the developing country. Kotey \& Mihret (2013) averred that as the global campaign towards higher education internationalisation intensifies, foreign qualifications are becoming increasingly valuable in order to satisfy the global demand for highly skilled labor. Students prefer higher education programmes that offer good employment potential or that enable them to become entrepreneurs. This motivates students to pursue foreign programmes that are available in their home countries. Cross boarder higher education aids in local skill development, and in increasing access to higher education system. Locals can acquire foreign qualifications at home thus reducing the likelihood of brain drain. In Zimbabwe for example, many students who want to study law, aviation, actuarial sciences and other specialized programmes have no option but to look for foreign higher education providers because the opportunities to study these programmes in local universities are either limited or non-existent.

In developing countries, foreign qualifications are generally perceived to offer greater prestige, opportunities for employment and prospects of a bright future for graduates. These perceptions motivate students to pursue programmes with foreign higher education providers based locally or internationally. Higher education institutions in many countries are engaging in collaborations with foreign institutions as a way of enhancing the quality of domestic programmes (Abeli 2010, Lee \& Healy 2006, Miranda 2008). In general, internationalisation of higher education has led to a rapid demand for internationally recognised qualifications and foreign higher education services. However, questions about the quality of teaching and learning, examinations, assessment, awards, and recognition of the foreign qualification by employers and quality assurance agencies continue to linger.

In Zimbabwe, although the number of universities increased from one in 1990 to the current 15, the number of potential 
students with the requisite entry qualifications still outstrips the number of places available in local higher education institutions. As a result, students either travel outside the country to pursue their studies or they enrol with locally based unregistered foreign institutions. For example every year the Government of Zimbabwe sponsors 4000 students to study at 15 universities in South Africa under the Presidential Scholarship Scheme (Zvavahera, 2014). This forms a crucial facet of the international dimension of Zimbabwe's higher education. Although student mobility has increased tremendously in the past decade, it failed to quench the thirst for higher education for a country with the highest literacy rate in Africa. In 1990, the Government of Zimbabwe opened up the higher education sector to allow private players involved in the provision of education to be granted permission to establish their own universities. Consequently, in addition to the establishment of six private universities, the last two decades witnessed the emergence of cross-border higher education programmes from foreign providers, new delivery modes (often based on information technologies) and different kinds of partnerships. Knight (2005) reported that the most common methods of cross-border higher education include overseas campuses, franchises, twinning arrangements, joint/double degrees, articulation, validation as well as distance/eLearning.

According to Knight (2005) franchises involve a foreign higher education institution authorising a local institution of another country to offer its programmes. The foreign institution awards the degree but the graduates must have their qualifications assessed by the local quality assurance agent. In twinning arrangements there is collaboration between the source higher education institution (foreign) and the local institution that allows students to earn degrees accredited and recognised in either country but awarded by the foreign higher education institution. For Double or Joint Degrees higher education providers from foreign and local countries form alliances to offer a program where the students receive awards from each higher education institution or a joint award from the cooperating institutions.

Knight (2005) avers that articulation is similar to twinning but the collaboration is more vibrant in the sense that students either have to spend some at each of the institutions or there is an exchange of teaching staff. The degree can be awarded by any of the two collaborating institutions. Validation enables the local (receiving) institution to award degrees originating from the source higher education institution. In open and distance learning/eLearning, programmes are offered and awarded by the institution in the source country to students based in any country in the world.

The challenges brought about by the opening up of the higher education to private and cross-border providers included proliferation of unrecognized, fly-by-night and rogue local and cross-border providers driven by commercial interests at the expense of maintaining quality and integrity of academic offerings. Stakeholders in Zimbabwe alleged that many of the foreign and new local higher education institutions provided sub-standard facilities, unqualified staff and lacked resources such as libraries and laboratories, and offered little value for money. Some stakeholders argued that these institutions also offered mainly irrelevant programmes such as Masters in Business Administration based on foreign universities offering knowledge inappropriate to graduates earmarked for the Zimbabwean economy. Similar reports regarding the compromised quality of foreign academic programmes have been documented and have received a lot of consideration by quality assurance watchdogs worldwide (Helms, 2008). In an effort to address quality assurance problems, the Council for Higher Education Accreditation (2009) documented guidelines for the identification of degree mills. In order to eliminate the activities of degree mills and ensure quality higher education, UNESCO (2009) encouraged national governments to formulate and use their legal and regulatory frameworks.

Knight (2005) avers that quality assurance is the key facet of professionalism in academia. Quality assurance is used by national governments worldwide as to manage and promote quality of delivery by higher education institutions. Quality assurance is key in the authentication of qualifications as well as student and staff mobility. Hayward (2006) advises that in the absence of effective and appropriate quality assurance mechanisms to ensure and improve quality socio-economic development cannot be fully realised. In line with this recommendation by Hayward (2006), the Government of Zimbabwe established a quality assurance agency, the Zimbabwe Council for Higher Education (ZIMCHE). ZIMCHE was mandated with the responsibility to guarantee and maintain quality in higher education by creating stable and reliable reference standards for registering and accrediting higher education providers, their programmes and courses. The objectives of registering and accrediting higher education institutions were to:

1. grant recognition to foreign and local higher education institutions, programmes and qualifications satisfying ZIMCHE's agreed minimum standards;

2. protect students from low-quality higher education provision and sub-standard qualifications byregulating of public, private and transnational higher education providers;

3. encourage and support institutions to exceed minimum standards;

4. provide information to stakeholders on recognized programmes and institutions in Zimbabwe and

5. engaging in international participation, co-operation and networking

Ever since ZIMCHE was established, no study has been done to ascertain the extent to which it has been able to 
regulate the players in the higher education sector. The fears of people of the presence of predator and fly by night higher education providers have still not been authenticated. This study was therefore carried out with the overall purpose of assessing the issues of quality associated with cross-border higher education provision in Zimbabwe. The study critically analysed the activities of ZIMCHE with respect to the registration and accreditation cases involving foreign providers as well as the outcomes of foreign qualifications assessments since the ZIMCHE legislation from 2009 to 2013.

\section{Methodology}

The study used the case study approach and was carried out during the months of February to March 2014 at the Zimbabwe Council for Higher Education. Two basic data-gathering techniques were used in this study. These were:

1. Review of documents of ZIMCHE relating to registration and accreditation cases involving foreign providers as well as the outcomes of foreign qualifications assessments from 2009 to 2012.

2. Interviews with staff from the ZIMCHE Directorates of Registration and Accreditation and Academic and Institutional Audit.

The face to face interviews sought to acquire in-depth understanding of the views of the ZIMCHE staff on the cases of registration and accreditation of cross-border higher education providers and their programmes as well as assessment of foreign qualifications. The researcher works for ZIMCHE and hence it was possible for her to obtain permission to assess the outcomes of the registration and accreditation cases for foreign higher education providers from 2009 to 2012. As a condition for approval for conducting research, the researcher was not allowed to divulge information on the names of the institutions involved. The researcher was also able to interview ZIMCHE staff using an interview guide in order to gather in-depth data on the quality of locally based cross-border higher education providers as well as the statistics and the reasons for non-recognition of certain foreign qualifications. A total of 12 key informants were interviewed.

\section{Results}

Interviews and documentary analysis revealed that ZIMCHE had implemented a quality assurance framework to manage quality in cross border higher education providers who offer programmes in Zimbabwe as well as qualifications that are obtained in foreign countries. This was done with the objective of regulating and sifting out sub-standard higher education programmes and providers as well protecting local learners from importing qualifications of low quality. The framework includes the following:

- registration and accreditation of institutions

- accreditation of all programmes and courses offered by all degree awarding institution in Zimbabwe

- $\quad$ periodic audits of institutions, programmes, facilities, staff, processes, governance

- $\quad$ paying attention to stakeholder complaints

- requirement for foreign institutions providing tuition to students in Zimbabwe to partner (have associate or affiliate relationship with a registered local higher education institution

All the 12 key informants were in agreement that cross-border higher education is beneficial. However, there is need to closely monitor the on-goings in order to weed out sub-standard and dubious foreign higher education providers. Some of these institutions do not comply with the national standards and often enrol students who do not meet the minimum entry requirements. They recommended that institutions of higher education should assist students who do not meet entry requirements by providing qualifying courses before admission. Some individuals and institutions are bogus and they sell qualifications to clients who do not merit obtaining them. The results will be presented under registration, accreditation and regulation of higher education providers and their programmes and assessment of qualifications obtained abroad.

\subsection{Registration, Regulation and Accreditation of Higher Education Institutions}

ZIMCHE closely monitored higher education providers who did not comply with the requirement to register before offering foreign and local degree programmes. All those institutions who do not comply are given an order of closure after which ZIMCHE then publishes the information in local press to inform the public on the status of the institutions. Figure 1 shows an excerpt from the Herald of 30 March 2014 in which ZIMCHE published the following statement to inform the public that it was obligatory for all higher education institutions, both local and foreign-based to be registered locally with ZIMCHE. Learners aspiring to pursue studies with higher education institutions were urged to verify the credibility of the institutions with ZIMCHE or host country Accreditation Authorities instead of relying solely on websites of the institutions.

"In terms of section 10 of the Zimbabwe Council for Higher Education Act (Chapter 25:27), ZIMCHE wishes to inform all stakeholders in higher education that the degrees offered by institutions which are not registered under the ZIMCHE Act are not recognised in Zimbabwe. It has come to the attention of ZIMCHE that there are 
colleges offering degrees in association with institutions domiciled outside Zimbabwe. The institutions must be registered in their countries. Further to that, they must be registered with ZIMCHE. Failure to register with ZIMCHE means that the institutions in Zimbabwe that are facilitating the teaching of these degrees are violating the ZIMCHE Act of 2006.

Universities such as Pan African College of Zimbabwe, Megham Consulting, United Theological College, University of Africa (not Africa University), Christ College (except programmes offered under affiliate-ship with Great Zimbabwe University) are officially closed. ZIMCHE has also nullified degree programmes from Triune, Calvary, Atlantic International and Harare Theological College. It is in the best interest of those intending to study abroad to check with ZIMCHE if the qualifications they intend to acquire would be recognised in Zimbabwe, especially if it is a professional qualifications which may require registration with a professional body in Zimbabwe,"

Some higher education institutions applied for registration with ZIMCHE. However, the final decision on whether to register the institution or not depended on the institution's ability to meet the minimum criteria set by ZIMCHE in terms of areas including governance and leadership structures, financial capacity to run the institution sustainably, qualifications of staff, infrastructure, equipment, student support systems and other criteria as contained in the ZIMCHE guidelines. Figure 2 shows the applications for registration as higher education providers that were received, rejected and accepted for the years 2009-2012.

It can be seen from Figure 1 that out of the three institutions that applied for registration in 2009, none was granted registration. For the period 2009-2012, a total of 22 institutions applied for registration but only four of those were registered. The institutions that failed to be registered did not meet the minimum standards are set out by ZIMCHE. Cross-border institutions who fail to register as universities are encouraged to offer their programmes in partnership with local registered universities. Figure 3 illustrates a case study of regulation of a higher education institution by ZIMCHE.

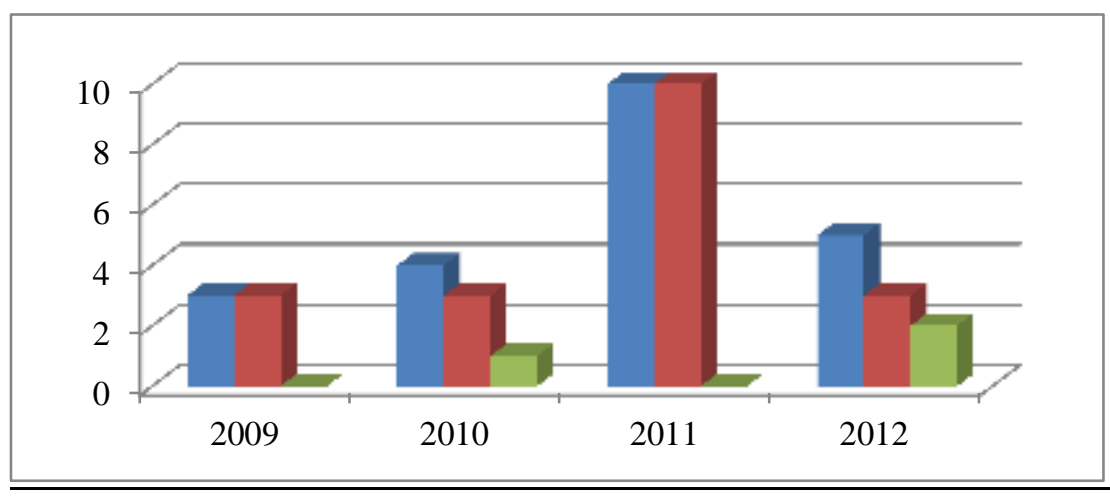

Figure 1. Applications for registration as higher education providers that were received (blue), rejected (maroon) and accepted (green) 2009-2012

\begin{tabular}{|l} 
- ZIMCHE closed down cross-border institution X \\
20 January \\
2011
\end{tabular}

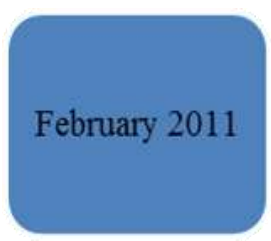

- Several meetings held with $\mathrm{X}$ highlighting illegality of running an unregistered higher education institution

- $\mathrm{X}$ was given advice to achieve legal status as follows:

- registering its own university or

- seeking associate/affiliateship with a local registered University

3 March

2011
- ZIMCHE informed the members of the public through the print media that X was an unregistered institution that had no authority to operate in Zimbabwe. 

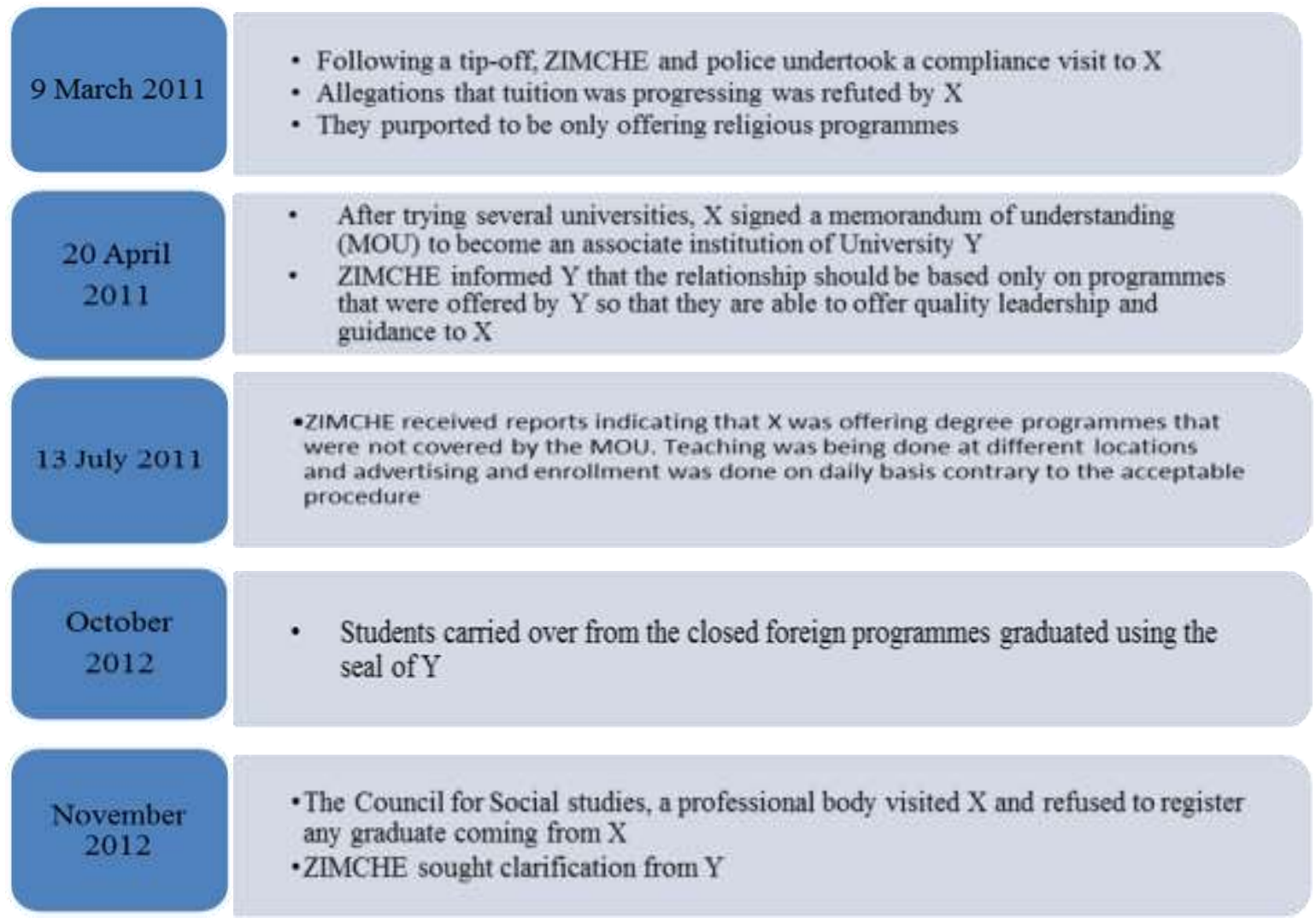

- The Council for Social studies, a professional body visited $\mathrm{X}$ and refused to register any graduate coming from $\mathrm{X}$

-ZIMCHE sought clarification from $Y$

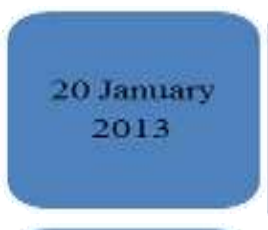

- After trying several HEls, $\mathrm{X}$ signed an MOU of associateship with University $\mathrm{Y}$

- ZIMCHE informed $Y$ that theY informed ZIMCHE that it had terminated its relationship with $\mathrm{X}$ but would have a teach-out prog for students who were already in-stream relationship should be based only on progs which were offered by $\mathrm{Y}$ so that they are able to offer leadership and guidance to $\mathrm{X}$

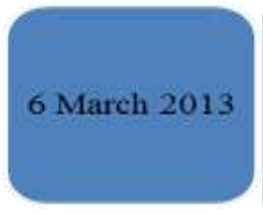

- ZIMCHE and $\mathrm{Y}$ visited $\mathrm{X}$ and found that:

- Lecture rooms were over-crowded;

- Facilities did not meet ZIMCHE stds;

- The library had no internet facilities and

- Teaching and learning resources were inadequate and did not meet minimum standards

6 June

2013
- ZIMCHE suspended all degree programmes at $\mathrm{X}$ until $\mathrm{Y}$ had put in place facilities to ensure sufficient curriculum delivery.

- $\mathrm{Y}$ was tasked to present to ZIMCHE the measures it would have put in place for adequate delivery of teach out progs

\subsection{Assessment of Foreign Qualifications}

Figure 2. Case study of regulation of higher education institution

The ZIMCHE quality assurance framework aids in streamlining recognition of qualifications obtained from accredited higher education institutions. Therefore, automatic recognition of qualifications is only for ZIMCHE accredited foreign and local higher education institutions.The ZIMCHE qualification assessment protects students and employers from bogus or sub-standard higher education providers and qualifications. The first stage in the assessment procedure is to determine whether the institution where the degree was obtained is registered in the country where the qualification was awarded and whether that particular degree programme is accredited. This verification is sought by ZIMCHE from quality assurance agencies in that country. The second stage is to check with the foreign institution whether the qualification is genuine and whether it is indeed the student written on the documents who obtained that qualification. After the verification process ZIMCHE will then assess the qualification for comparability with similar local qualifications. The certificates and transcripts are sent to local experts in the field of study so that they can assess issues of the curriculum, entry requirements, duration of study and rigor. If the qualifications are found to be comparable, a certificate is given to the qualification holder testifying that the qualification is comparable to those offered locally. The 
qualification holder can then use the certificate from ZIMCHE for employment purposes or for further education. Figure 3 shows the outcome of qualifications that were assessed from 2009 to 2013.

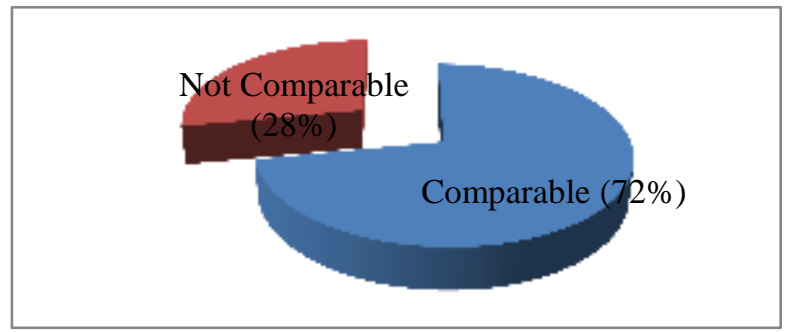

Figure 3. Outcome of foreign qualifications assessment (2009 to 2013)

Twenty-eight percent of the qualifications were found to be authentic but not of comparable quality to similar programmes offered in Zimbabwe. The reasons for lack of comparability related to entry requirements, duration of study, content and rigor. Some programme were very good in terms of their curriculum content but were not delivered at the same quality level as that of the originating institution and country. This was because of the local infrastructure and facilities as well as the quality of academic staff. The purpose of accreditation was therefore to ensure compliance with local requirements for degree programmes. Cross-border higher education providers must be registered and accredited in their country of origin and their programmes should compare favourably with similar programmes offered in Zimbabwean institutions. Table 1 shows the distribution of reasons for lack of comparability of qualifications.

Table 1. Percentage distribution of reasons for lack of comparability

\begin{tabular}{lc}
\hline Reason & Percentage $(\%)$ \\
\hline Content coverage in terms of breath, depth and exposure to industry and commerce as well as & 50 \\
research and practical learning & 21 \\
Duration of programmes & 20 \\
Level of programme e.g. Honours versus General & 9 \\
Entry requirements & 100 \\
TOTAL & \\
\hline
\end{tabular}

As shown in Table 1, the major reason for lack of comparability (50\% of cases) was due to differences in programme and course content in terms of breath, depth and exposure to industry and commerce as well as research and practical learning. Course duration and level of programme contributed $21 \%$ and $20 \%$ of reasons for lack of comparability respectively. Differences in entry requirements accounted for $9 \%$ of the reasons for lack of comparability.

Table 2 shows the origin of the foreign qualifications and the numbers of assessments done and those that were approved as well as those that were approved.

Table 2. Source of foreign qualifications, total assessed, approved and not approved.

\begin{tabular}{lccc}
\hline Country & Approved & Not approved & Total \\
\hline South Africa & 19 & 15 & 34 \\
\hline Kenya & 12 & 0 & 9 \\
UK & 7 & 2 & 9 \\
USA & 4 & 5 & 8 \\
Zimbabwe & 4 & 4 & 4 \\
Russia & 4 & 0 & 4 \\
Cuba & 3 & 1 & 3 \\
Korea & 3 & 0 & 3 \\
Algeria & 3 & 0 & 3 \\
Uganda & 3 & 0 & 3 \\
Netherlands & 0 & 3 & 3 \\
Namibia & 0 & 3 & 3 \\
India & 0 & 3 & 3 \\
Botswana & 1 & 2 & 2 \\
Saudi Arabia & 0 & 2 & 2 \\
Italy & 0 & 2 & 2 \\
Malawi & 0 & 2 & 2 \\
Australia & 0 & 2 & 2 \\
Canada & 0 & 2 & 2 \\
Malaysia & 2 & 1 \\
Mauritius & 12 & 0 & 1 \\
Cyprus & 7 & 0 & 1 \\
Rwanda & 4 & 0 & 1 \\
Spain & 4 & 0 & 2 \\
China & 4 & 0 & \\
Romania & 3 & 0 & \\
Lesotho & 3 & 0 & \\
\hline
\end{tabular}


Table 2 shows that qualifications from many countries across the globe were assessed with the majority originating from South Africa.

\section{Discussion}

The findings revealed that internationalisation of higher education affords several opportunities and advantages but it can also negatively impact on the quality of higher education provision if certain activities are not constantly monitored. These include sub-standard and dubious foreign higher education providers who often enrol students who do not meet the minimum entry requirements as well as degree mills who sell qualifications to clients who do not merit obtaining them. Out of all the qualifications assessed from 2009-2013, 28 percent were found not comparable with similar local qualifications in terms of curriculum content, rigor, duration of study and entry requirements. The lessons from the study include the need for higher education institutions to enrol students who meet nationally agreed entry requirements as well as introducing qualifying courses before admission of those who do not initially meet the required standards for entry. Quality assurance bodies and institutions of higher learning should continue to collaborate with similar bodies globally in order to share best practices on quality assurance issues and setting of minimum standards.

\section{Conclusion and Recommendations}

It has been argued that most cross-border higher education providers are worried about maximising their profits thereby negatively impacting on the reputation of providers of cross-border higher education by offering low-quality service and at times worthless qualifications. The recommendations of the study pointed towards the need for continued regional and continental collaboration among quality assurance bodies and institutions of higher learning to improve the quality of higher education delivery. Students who do not meet entry requirements need to pass through a qualifying course before admission.

\section{References}

Abeli, W. (2010). Higher Education and Development: A Critical Nexus. In Kotecha, P. (Ed.), Investment in Higher Education for Development: New Directions, SARUA Leadership Dialogue Series, 2(2).

Bashir, S. (2007). Trends in International Trade in Higher Education: Implications and Options for Developing Countries. World Bank: USA

Council for Higher Education Accreditation. (2009). Towards Effective Practice: Discouraging Degree Mills in Higher Education UNESCO.

Hayward, F. M., (2006). Quality Assurance and Accreditation of Higher Education in Africa Paper presented at the Conference on Higher Education Reform in Francophone Africa: Understanding the Keys of Success Ouagadougou, Burkina Faso.

Helms, R. M. (2008). Trans-national Education in China: Key Challenges, Critical issues and Strategies for Success. The Observatory on Borderless Higher Education, London.

Knight, J. (2005). Cross-border Education: Programs and Providers on the Move. CBIE Millennium Research Monograph, 10. Canadian Bureau for International Education. Ottawa, Canada.

Knight, J. (1999). Internationalisation of Higher Education. in Quality and Internationalisation in Higher Education, edited by OECD. pp. 13-18 Paris: OECD.

Kotey, B., \& Mihret, D. (2013). Internationalisation and Globalisation of Higher Education: Implications for Africa's HigherEducation System. DEHub Monograph Series.

Lee, M., \& Healy, S. (2006). Higher Education in Southeast Asia: An Overview. In Higher Education in Southeast Asia. UNESCO Asia and Pacific Regional Bureau for Education.

Miranda, X. (2008). Regional Integration and Internationalization of Higher Education in Latin America and the Caribbean. In Gazzola, L. and Didriksson, A. (Eds.), Trends in Higher Education in Latin America and the Caribbean, International Institute of UNESCO for Higher Education in Latin America and the Caribbean.

Ninnes, P., \& Hellstén, M. (eds.). (2005). Internationalizing Higher Education: Critical Explorations of Pedagogy and Policy. Paris: OECD. http://dx.doi.org/10.1007/1-4020-3784-8

Zvavahera, P. (2014) The Presidential Scholarship Programme in Zimbabwe: A living case of the political will in promoting regionalisation in higher education. Journal of Case Studies in Education, 6, 1-9.

\section{(cc) BY}

This work is licensed under a Creative Commons Attribution 3.0 License. 